\title{
Comorbidity of Attention-Deficit/Hyperactivity Disorder (ADHD) in Children with Epilepsy, Egyptian Study
}

\author{
Nahed Salah El-din Ahmed1, Maha Ali Nada1, Randa Mohamed Amin1, Omar Sayed Khalifa Ali², \\ Mohamed Hamdy Ibrahim ${ }^{1}$
}

${ }^{1}$ Neurology Department, Faculty of Medicine, Ain Shams University, Cairo, Egypt

${ }^{2}$ Neurology Department, Faculty of Medicine, Minia University, Cairo, Egypt

Email: mohamedhamdy_neuro2007@yahoo.com

How to cite this paper: Salah El-din Ahmed, N., Ali Nada, M., Mohamed Amin, R., Sayed Khalifa Ali, O. and Hamdy Ibrahim, M. (2020) Comorbidity of Attention-Deficit/Hyperactivity Disorder (ADHD) in Children with Epilepsy, Egyptian Study. Neuroscience \& Medicine, 11, 119-129. https://doi.org/10.4236/nm.2020.114014

Received: September 30, 2020

Accepted: December 4, 2020

Published: December 7, 2020

Copyright $\odot 2020$ by author(s) and Scientific Research Publishing Inc. This work is licensed under the Creative Commons Attribution-NonCommercial International License (CC BY-NC 4.0). http://creativecommons.org/licenses/by-nc/4.0/ (c) (i) (8) Open Access

\begin{abstract}
Background: Epilepsy is one of the most common neurological conditions with about 65 million people affected worldwide. It is also a common condition in children, where its prevalence is approximately $3.2-5.5 / 1000$ in the developed world. Children with epilepsy (CWE) experience not only seizures but also multiple cognitive, behavioral, and emotional problems. ADHD is one of the more common comorbidities of childhood epilepsy. Objectives: To discuss the relationship between childhood epilepsy and comorbidities especially ADHD. Study Design: This is a prospective observational analytical cross-sectional study carried out on one hundred and fifteen patients at Ain Shams University and Nasr-city Health Insurance out-patient clinics, Cairo, Egypt fulfilling the inclusion criteria. Patients were selected by simple random sample. Results: ADHD is very common epilepsy comorbidity in Egyptian epileptic children with under-diagnosis and treatment. Conclusion: Frequent assessment for ADHD in epileptic children is mandatory for better quality of life.
\end{abstract}

\section{Keywords}

Attention Deficit, Seizures, Comorbidity, Egyptian Study

\section{Introduction}

Epilepsy is one of the most common neurological conditions with about 65 million people affected worldwide. It is also a common condition in children, where its prevalence is approximately $3.2-5.5 / 1000$ in the developed world [1]. 
Children with epilepsy (CWE) experience not only seizures but also multiple cognitive, behavioral, and emotional problems [2].

Epidemiological studies in Europe, Scandinavia and the USA have confirmed a high rate of psychiatric disorder in CWE, typically around 35\% to $50 \%$.

ADHD is one of the more common comorbidities of childhood epilepsy [3]. It is typically reported in about $30 \%$ of children with epilepsy compared to $3 \%$ $6 \%$ of controls [4].

Approximately 70,000 school-age children in the UK have epilepsy and about 20,000 of these will have both epilepsy and ADHD. However, probably only fraction is treated for ADHD. Reluctance to treat may be related to diagnostic issues but is more likely to be related to concerns about possible seizure exacerbation [5].

Many studies have demonstrated the importance of ADHD medication treatment both in healthy children and in CWE. The importance of consideration for ADHD treatment was recently highlighted again by a large population-based study by [6]. In this review we will discuss briefly the childhood epilepsy and it is common comorbidities especially ADHD and finally the management of AD.

\section{Subjects and Methods}

This is a prospective observational analytical cross-sectional study. The study was carried out at Ain Shams University and Nasr-city Health Insurance out-patient clinics, Cairo, Egypt. Patients were selected by simple random sample. One hundred and fifteen patients fulfilling the inclusion criteria.

\section{Inclusion Criteria:}

Age group between 4 and 16 years, both sexes. Children with diagnosis of epilepsy diagnosed according to international league against epilepsy criteria. Both medicated or drug naive patients.

\section{Exclusion Criteria:}

Patient with symptomatic epilepsy. Patient with severe or profound intellectual disability (defined as intelligence quotient (IQ) less than (35) patient with comorbid chronic systemic illness known to affect attention and activity.

Steps of examination:

Step one:

All patients were subjected to the following: Full personal history. Full medical and neurological history including:

Detailed history of epilepsy (type-duration-medication-frequency of seizure). Detailed history of ADHD if previously diagnosed (duration and medication). Detailed history of psychiatric disorders. Detailed history of intellectual disability. Detailed history of medical disorder and current medication. Family history of ADHD, epilepsy and psychiatric disease.

General and neurological examination. Routine investigation of epileptic patient (Brain imaging-Electroencephalogram routine or sleep according to type of epilepsy-Complete blood count). 
Step II: Patients fulfill inclusion criteria were subjected to:

Wechsler Intelligence Scale for Children (WISC) Arabic version for age group (5 - 16 years).

Aim: Assessment of intellectual abilities and cognitive functions

- The test was administrated by clinical psychologist.

1) Quality of Life in Childhood Epilepsy Questionnaire: QOLCE-55

2) Conners' rating scale

- Conners' rating scales revised were introduced by professor Keith Conners in 1997.

- The original Conners' rating scales were introduced in 1989.

\begin{tabular}{cc}
\hline CONNERS' SCALE & \\
\hline$>70$ & Significant \\
$66-70$ & Moderate \\
$61-65$ & Mild atypical \\
$56-60$ & Slightly atypical \\
$45-55$ & Typical \\
\hline
\end{tabular}

- The test was administrated by clinical psychologist.

\section{Statistical Methods}

The collected data were coded, tabulated, and statistically analyzed using IBM SPSS statistics (Statistical Package for Social Sciences) software version 22.0, IBM Corp., Chicago, USA, 2013.

Descriptive statistics were done for quantitative data as minimum\& maximum of the range as well as mean \pm SD (standard deviation) for quantitative normally distributed data, while it was done for qualitative data as number and percentage.

Inferential analyses were done for quantitative variables using independent t-test in cases of two independent groups with normally distributed data. In qualitative data, inferential analyses for independent variables were done using Chi square test for differences between proportions. While correlations were done Pearson correlation for numerical parametric data was used. The level of significance was taken at $\mathrm{P}$ value $<0.050$ is significant, otherwise is non-significant.

\section{Results}

In this cross-sectional, observational study children diagnosed with epilepsy according to ILAE's criteria attending the outpatient clinics of neurology department Ain-Shams University Hospital \& Nasr City Health Insurance Hospital were screened for eligibility to inclusion and exclusion criteria.

From 195 child presented, 80 child were excluded, of the excluded group 45 were illegible age (less than 4 years or more than 16 years), 10 due to severe in- 
tellectual disability (IQ less than 35), 25 with symptomatic epilepsy due to known brain injury as shown by MRI.

- Descriptive data:

1) Demographic data (Table 1, Figure 1, Figure 2)

Sex: Study was carried on 115 epileptic children among them 57 males (49.57\%) and 58 females (50.43\%).

Age: With age range $5-16$ years and mean age $9.7 \pm 2.91$ years, the study population divided into 3 sub-groups:

○ 5 - 6 Years 17 child (14.87\%).

○ 7 - 11 Years 69 child (60\%).

○ >11 Years $29(25.22 \%)$.

Table 1. Basic descriptive data of study group.

\begin{tabular}{|c|c|c|}
\hline Age & \multicolumn{2}{|c|}{ Range $(5-16)$ mean $9.7 \pm 2.9$ years } \\
\hline & 4 - 6 Years & $17(14.78 \%)$ \\
\hline \multirow[t]{3}{*}{ Age groups } & 7 - 11 Years & $69(60 \%)$ \\
\hline & $>11$ Years & $29(25.22 \%)$ \\
\hline & Male & $57(49.57 \%)$ \\
\hline \multicolumn{3}{|l|}{ Sex } \\
\hline & Female & $58(50.43 \%)$ \\
\hline Previous diagnosis of ADHD & \multicolumn{2}{|c|}{13 children $(11.3 \%)$} \\
\hline +ve family history of epilepsy & \multicolumn{2}{|c|}{23 children $(20 \%)$} \\
\hline +ve history of febrile seizure & \multicolumn{2}{|c|}{22 children (19.1\%) } \\
\hline \multirow{2}{*}{ School attendance } & Yes & $104(90.43 \%)$ \\
\hline & No & $11(9.57 \%)$ \\
\hline
\end{tabular}

Table 2. Epilepsy characteristics in study population.

\begin{tabular}{ccc}
\hline Type of epilepsy & Focal & $75(65.2 \%)$ \\
& Generalized & $40(34.78 \%)$ \\
\hline Age of $1^{\text {st }}$ seizure & Range & Mean \pm SD \\
\hline Duration of epilepsy & $1-14$ & $7.4 \pm 3.1$ \\
\hline Presence of seizure in last 3 months & $0-9$ & $2 . .2 \pm 2$ \\
\hline Antiepileptic medication & Yes & $58(50.43 \%)$ \\
\hline Epileptic discharge in the most recent EEG & No & $9(79.56 \%)$ \\
\hline
\end{tabular}




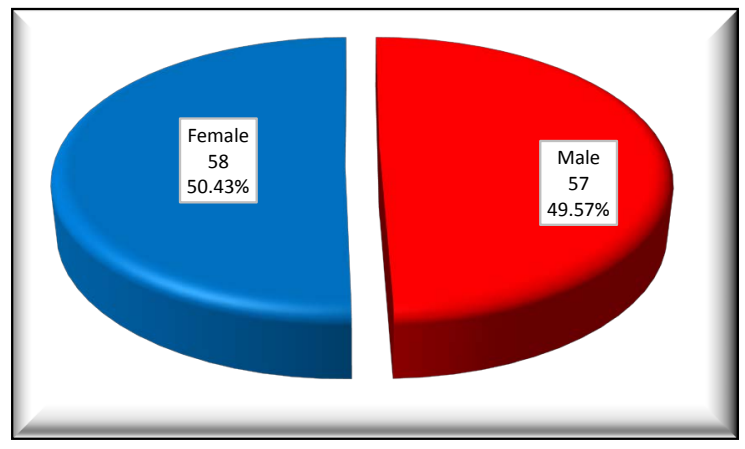

Figure 1. Sex distribution in study group.

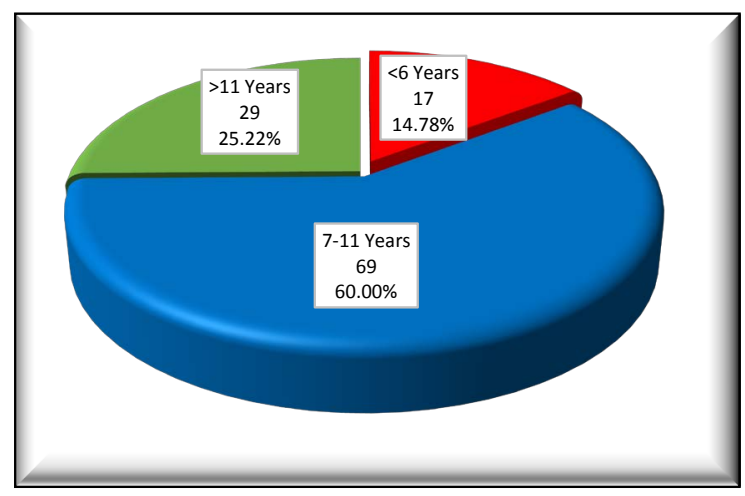

Figure 2. Age groups in study population.

2) Epilepsy characteristics (Table 2):

- Type of epilepsy

From 115 children included in the study 75 (62.22\%) found to have focal epilepsy and 40 (34.78\%) with generalized epilepsy (Figure 3).

3) ADHD diagnosis according to DSM 5 criteria (Table 3 ):

ADHD presence: Among the 115 epileptic children, 36 found to have ADHD (31.3\%) and 79 non-ADHD (68\%).

Conner's rating scale:

- Total ADHD score in ADHD children

The severity of ADHD according to Conner's Parent Rating Scale for ADHD applied to all ADHD children who take treatment or not, 11 children with slight atypical (30.55\%), 13 with mild symptoms (36.11\%), 6 moderate symptoms (16.66\%) and 6 with severe symptoms (16.66\%) (Table 4).

- Inattention score in ADHD children

In the inattention score applied to all ADHD children who take treatment or not, 2 children were normal (5.55\%), 3 children were slight atypical (8.33\%), 11 mild inattention (30.55\%), 13 with moderate inattention $(36.11 \%)$ and 7 with severe inattention (19.44\%) (Table 5).

- Comparative data

1) comparison between demographic data in ADHD and non-ADHD

$\circ$ The relation between the age and ADHD presence 


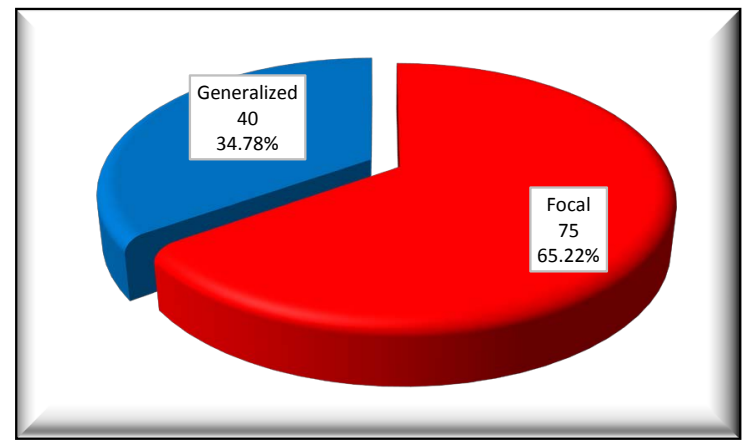

Figure 3. Type of epilepsy in study.

Table 3. ADHD presence and type.

\begin{tabular}{lcc}
\hline & ADHD & $36(31.3 \%)$ \\
\cline { 2 - 3 } ADHD presence & Non-ADHD & $79(68.7 \%)$ \\
\hline \multirow{2}{*}{ Type of ADHD } & Combined & $15(41.67 \%)$ \\
& Inattention & $19(52.78 \%)$ \\
& Hyperactive & $2(5.56 \%)$ \\
\hline
\end{tabular}

Table 4. DSM IV total in ADHD children.

\begin{tabular}{ccc}
\hline & DSM IV Total in ADHD & \\
\hline & $\mathrm{N}$ & $\%$ \\
\hline Slight atypical & 11 & $30.55 \%$ \\
Mild & 13 & $36.11 \%$ \\
Moderate & 6 & $16.66 \%$ \\
Severe & 6 & $16.66 \%$ \\
Total & 36 & 100.00 \\
\hline
\end{tabular}

Table 5. DSM IV inattention score in ADHD children.

\begin{tabular}{ccc}
\hline & DSM IV inattention in ADHD children & \\
\hline N & $\%$ \\
\hline Normal & 2 & 5.55 \\
Slight atypical & 3 & 8.33 \\
Mild & 11 & 30.55 \\
Moderate & 13 & 36.11 \\
Severe & 7 & 19.44 \\
Total & 36 & 100.00 \\
\hline
\end{tabular}

The ADHD group was significantly younger in age with age range (5 - 14), mean $8.8 \pm 2.5$, while non ADHD was significantly older with age range (5 - 16) mean $10.2 \pm 2.9$ (P value 0.02) (Table 6, Figure 4).

$\circ$ The relation between age groups and ADHD presence 
There was no statically significant difference between age groups preschool ( $\leq 6$ years), school ( $>6-\leq 11$ years) and adolescence $(>11)$ (Table 7, Figure 5 ).

- The relation between the sex and ADHD presence

There was no significant difference in sex between ADHD and non-ADHD groups.

There were 57 male included (49.5\%), 17 were ADHD (29.8\%), 57 were non-ADHD (70.1\%).

There were 58 female included (55.5\%), 19 were ADHD (32.7\%), 39 were normal (67.2\%) (Table 8, Figure 6).

2) Comparison between epilepsy characteristics in ADHD and non-ADHD groups:

$\circ$ Type of epilepsy and ADHD

There was no statically significant difference in ADHD co-morbidity between focal and generalized epilepsy groups.

From the 75 children with focal epilepsy 22 were ADHD (29.3\%), 53 were non-ADHD (70.6\%).

From the 40 children with generalized epilepsy, 14 were ADHD (35\%), 26 were non-ADHD (Table 9, Figure 7).

Table 6. The relation between the age and ADHD presence.

\begin{tabular}{|c|c|c|c|c|c|c|c|c|}
\hline \multirow{2}{*}{ Age } & \multicolumn{6}{|c|}{ ADHD presence } & \multicolumn{2}{|c|}{ T-Test } \\
\hline & \multicolumn{3}{|c|}{ Yes } & \multicolumn{3}{|c|}{ No } & $\mathrm{T}$ & $\mathrm{P}$-value \\
\hline Range & 5 & - & 14 & 5 & - & 16 & & \\
\hline Mean \pm SD & 8.861 & \pm & 2.532 & 10.215 & \pm & 2.994 & -2.355 & $0.020^{\star}$ \\
\hline
\end{tabular}

Table 7. The relation between age groups and ADHD presence.

\begin{tabular}{|c|c|c|c|c|c|c|c|c|}
\hline \multirow{3}{*}{ Age groups } & \multicolumn{6}{|c|}{ ADHD presence } & \multirow{2}{*}{\multicolumn{2}{|c|}{ Chi-Square }} \\
\hline & \multicolumn{2}{|c|}{ Yes } & \multicolumn{2}{|c|}{ No } & \multicolumn{2}{|c|}{ Total } & & \\
\hline & $\mathrm{N}$ & $\%$ & $\mathrm{~N}$ & $\%$ & $\mathrm{~N}$ & $\%$ & $\mathrm{X}^{2}$ & $\mathrm{P}$-value \\
\hline 5 - 6 Years & 9 & 52.94 & 8 & 47.06 & 17 & 100.00 & & \\
\hline 7 - 11 Years & 20 & 28.99 & 49 & 71.01 & 69 & 100.00 & & \\
\hline$>11$ Years & 7 & 24.14 & 22 & 75.86 & 29 & 100.00 & 4.566 & 0.102 \\
\hline Total & 36 & 31.30 & 79 & 68.70 & 115 & 100.00 & & \\
\hline
\end{tabular}

Table 8. The relation between sex and ADHD presence.

\begin{tabular}{ccccccccc}
\hline & \multicolumn{9}{c}{ ADHD presence } & \multicolumn{2}{c}{ Chi-Square } \\
\cline { 2 - 6 } Sex & \multicolumn{2}{c}{ Yes } & \multicolumn{2}{c}{ No } & \multicolumn{2}{c}{ Total } & & \\
\cline { 2 - 6 } & $\mathrm{N}$ & $\%$ & $\mathrm{~N}$ & $\%$ & $\mathrm{~N}$ & $\%$ & $\mathrm{X}^{2}$ & P-value \\
\hline Male & 17 & 29.82 & 40 & 70.18 & 57 & 100.00 & & \\
Female & 19 & 32.76 & 39 & 67.24 & 58 & 100.00 & 0.115 & 0.734 \\
Total & 36 & 31.30 & 79 & 68.70 & 115 & 100.00 & & \\
\hline
\end{tabular}


Table 9. The relation between type of epilepsy and ADHD presence.

\begin{tabular}{|c|c|c|c|c|c|c|c|c|}
\hline \multirow{3}{*}{ Type of epilepsy } & \multicolumn{6}{|c|}{$\mathrm{ADHD}$ presence } & \multirow{2}{*}{\multicolumn{2}{|c|}{ Chi-Square }} \\
\hline & \multicolumn{2}{|c|}{ Yes } & \multicolumn{2}{|c|}{ No } & \multicolumn{2}{|c|}{ Total } & & \\
\hline & $\mathrm{N}$ & $\%$ & $\mathrm{~N}$ & $\%$ & $\mathrm{~N}$ & $\%$ & $\mathrm{X}^{2}$ & $\mathrm{P}$-value \\
\hline Focal & 22 & 29.33 & 53 & 70.67 & 75 & 100.00 & & \\
\hline Generalized & 14 & 35.00 & 26 & 65.00 & 40 & 100.00 & 0.390 & 0.533 \\
\hline Total & 36 & 31.30 & 79 & 68.70 & 115 & 100.00 & & \\
\hline
\end{tabular}

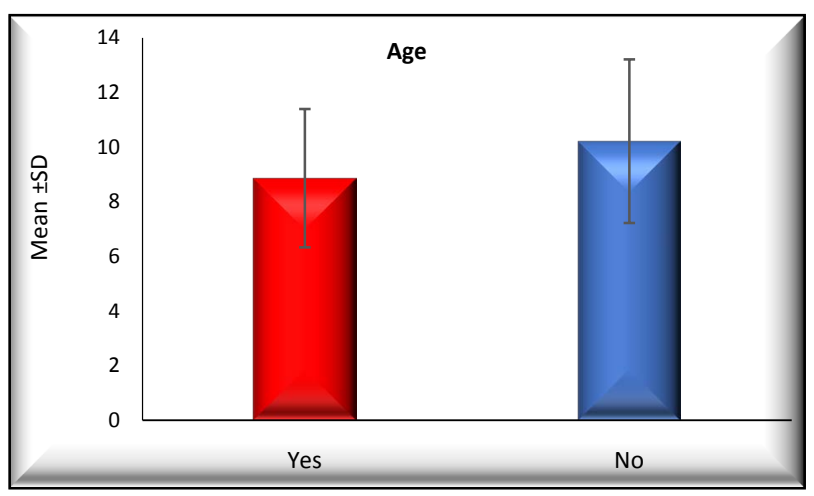

Figure 4. The relation between the age and ADHD presence.

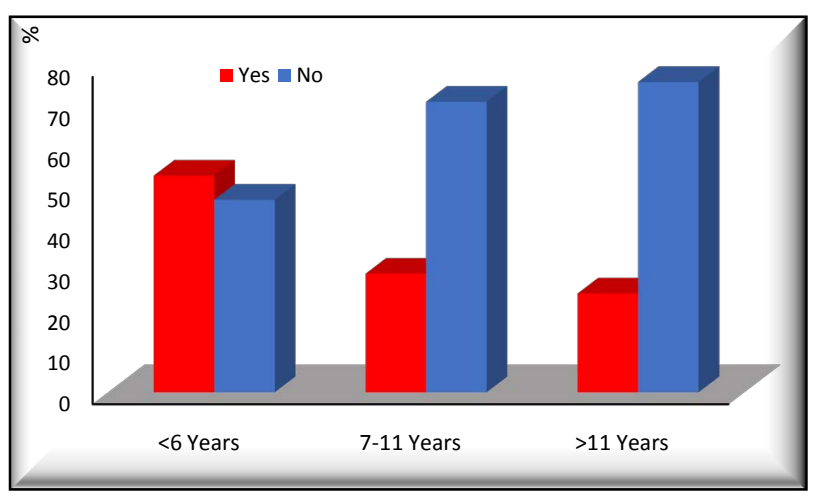

Figure 5. The relation between age groups and ADHD presence.

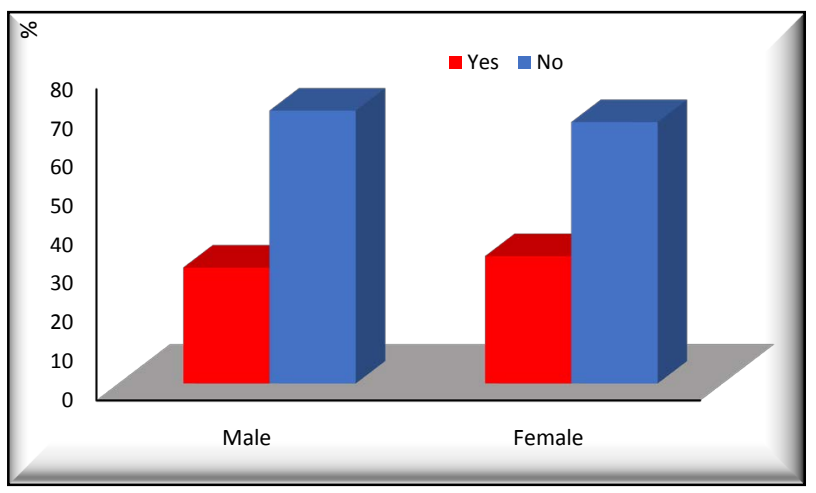

Figure 6. The relation between sex and ADHD presence. 


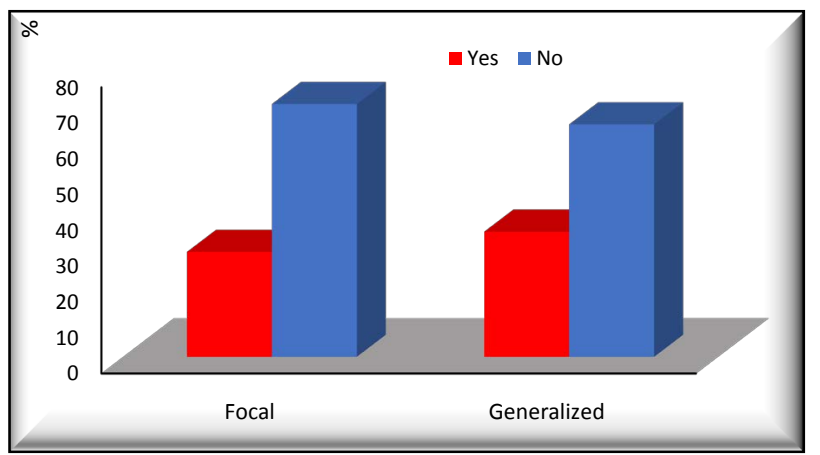

Figure 7. The relation between type of epilepsy and ADHD presence.

\section{Discussion}

Epilepsy is a "spectrum" disorder, with associated cognitive and psychiatric impairment in approximately half of the patients, Attention-deficit-hyperactivity disorder (ADHD) is the most common comorbidity in children with epilepsy, occurring in about $30 \%$ of them, with equal comorbidity in boys and girls, in contrast to the pattern in the general population with male predominance, The reason for ADHD comorbidity is debated but in most cases no other cause has been found and it has been concluded that the most likely explanation is an underlying factor causing both conditions.

The aim of our study was to highlight the comorbidity and clinical impacts of ADHD in Egyptian children and adolescents with epilepsy regarding its different characteristics and effect on quality of life.

We carried out a cross-sectional study of 115 children with epilepsy, full medical and neurological history and examination obtained, and assessed for ADHD comorbidity using the DSM5 criteria then we used Conner's Parent Rating Scale for ADHD, Wechsler Intelligence Scale for Children and Quality of Life in Childhood Epilepsy Questionnaire (QOLCE-55) to assess the study population.

We founded that 36 children had ADHD (31.3\%), 19 children (52.7\%) were inattentive type as the most common type then the combined type 15 (41.6\%) and lastly the hyperactive type with 2 children (5.5\%).

These findings are similar to the results of many studies which show high ADHD comorbidity with predominance of inattention type [6] [7] [8].

For example it was found that 75 children and compared them with 62 controls. ADHD was found in $31 \%$ of the children with epilepsy and in $6 \%$ of the controls. Dunn et al. (2003) studied 175 children, a total of 66 (38\%) had ADHD of one type or another, 20 combined type, 42 predominantly inattentive types and four predominantly hyperactive-impulsive types.

Review of ILAE concluded that ADHD is reported as $30 \%-40 \%$ of children with epilepsy compared to $3 \%-6 \%$ of control, overall a rate 2.5 to 5.5 times higher than in otherwise healthy children without seizures [1] [2] [3].

In our study from the 36 epileptic children diagnosed with ADHD, 23 (66.6\%) were 1st time to be diagnosed with ADHD. 
ILAE founded that ADHD is under-diagnosed and under-treated in children with epilepsy [2]. That is why in 2018 ILAE recommend that ADHD screening should be performed from 6 years of age, or at diagnosis of epilepsy, and repeated annually and reevaluated after change of antiepileptic drug (AED) [1].

The present study found equal ADHD comorbidity in both sexes, with males comorbidity $(29.8 \%)$ compared to $(32.7 \%)$ in females with no statically significant difference.

Studies evaluating children with new-onset epilepsy found male sex was not predictive of higher rates of ADHD [6]. Similar findings were noted in studies of children with preexisting epilepsy [5].

In the general population, $\mathrm{ADHD}$ is 3- to 7-fold more common in boys than girls. However, most studies document equal sex distributions of ADHD in children with epilepsy [6].

ILAE concluded that no increased risk in boys with epilepsy compared to girls with epilepsy [2].

We founded that Lower age of onset of 1st seizure was associated with higher ADHD co-morbidity with nearly statically significant ratio ( $P$ value 0.051$)$, In the ADHD group mean age of 1 st seizure was $6.6 \pm 2.9$, In the non-ADHD group mean was $7.8 \pm 3.2$ years.

Although some studies show a higher prevalence of ADHD among those with earlier age of epilepsy onset, the literature is conflicted on this topic. Alfstad et al. (2016) demonstrated that early onset of epilepsy increased the risk of developing psychiatric disorders.

In contrast, Hermann et al. (2007) found no significant correlation between younger age at seizure onset and higher rates of $\mathrm{ADHD}$ in a cohort of children with newly diagnosed epilepsy. Similarly, Kral et al. (2016) found no association between earlier age at epilepsy onset and ADHD in a retrospective cohort study of children with epilepsy.

ILAE concluded that impact of early seizure onset on development of ADHD was unclear [2].

In our study there was no statically significant difference in ADHD co-morbidity between focal and generalized epilepsy groups, From the 75 children with focal epilepsy 22 were ADHD (29.3\%), From the 40 children with generalized epilepsy, 14 were ADHD (35\%).

\section{Conclusion}

This evidence suggests that ADHD is very common epilepsy comorbidity in Egyptian epileptic children with under-diagnosis and treatment. So frequent assessment for ADHD in epileptic children is mandatory for better quality of life.

\section{Recommendations}

1) Assessment of all children with epilepsy for ADHD annually after the age of 6 years. 
2) Treat all children with epilepsy and ADHD with appropriate treatment.

3) Subsequent study on a larger group of patients to support our results.

\section{Conflicts of Interest}

The authors declare no conflicts of interest regarding the publication of this paper.

\section{References}

[1] Aaberg, K.M., Surén, P., Søraas, C.L., Bakken, I.J., Lossius, M.I., Stoltenberg, C. and Chin, R. (2017) Seizures, Syndromes, and Etiologies in Childhood Epilepsy: The International League Against Epilepsy 1981, 1989, and 2017 Classifications Used in a Population-Based Cohort. Epilepsia, 58, 1880-1891.

https://doi.org/10.1111/epi.13913

[2] Auvin, S., Wirrell, E., Donald, K.A., Berl, M., Hartmann, H., Valente, K.D. and Aihara, M. (2018) Systematic Review of the Screening, Diagnosis, and Management of ADHD in Children with Epilepsy. Consensus Paper of the Task Force on Comorbidities of the ILAE Pediatric Commission. Epilepsia, 59, 1867-1880.

https://doi.org/10.1111/epi.14549

[3] Besag, F., Gobbi, G., Caplan, R., Sillanpää, M., Aldenkamp, A. and Dunn, D.W. (2016) Psychiatric and Behavioural Disorders in Children with Epilepsy (ILAE Task Force Report): Epilepsy and ADHD. Epileptic Disorders, 18, 1-86.

https://doi.org/10.1684/epd.2016.0809

[4] Camfield, P. and Camfield, C. (2015) Incidence, Prevalence and Aetiology of Seizures and Epilepsy in Children. Epileptic Disorders, 17, 117-123. https://doi.org/10.1684/epd.2015.0736

[5] Dunn, D.W. (2014) Focusing on ADHD and Attention in Children with Epilepsy. Epilepsy and Behavior, 37, 308-309. https://doi.org/10.1016/j.yebeh.2014.06.022

[6] Hermann, B., Jones, J., Dabbs, K., Allen, C.A., Sheth, R., Fine, J. and Seidenberg, M. (2007) The Frequency, Complications and Aetiology of ADHD in New Onset Paediatric Epilepsy. Brain, 130, 12-48. https://doi.org/10.1093/brain/awm227

[7] Kwong, K.L., Lam, D., Tsui, S., Ngan, M., Tsang, B., Lai, T.S. and Lam, S.M. (2016) Self-Esteem in Adolescents with Epilepsy: Psychosocial and Seizure-Related Correlates. Epilepsy and Behavior, 63, 118-122. https://doi.org/10.1016/j.yebeh.2016.07.032

[8] Reilly, C., Atkinson, P., Das, K.B., Chin, R.F., Aylett, S.E., Burch, V. Neville, B.G. (2014) Screening for Mental Health Disorders in active Childhood Epilepsy: Population Based Data. Epilepsy Research, 108, 1917-1926.

https://doi.org/10.1016/j.eplepsyres.2014.09.028 